\title{
High-Performance Insulator Structures for Accelerator Applications
}

\author{
S. E. Sampayan, G. J. Caporaso, D. M. Sanders, \\ R. D. Stoddard, D. O. Trimble, \\ J. Elizondo, M. L. Krogh, T. F. Wieskamp \\ AlliedSignal Corporation, FM\&T
}

This paper was prepared for submittal to the

1997 Particle Accelerator Conference

Vancouver, B. C. Canada

May 12-16, 1997

May 1997

This is a preprint of a paper intended for publication in a journal or proceedings. Since changes may be made before publication, this preprint is made available with the understanding that it will not be cited or reproduced without the permission of the author. 


\section{DISCLAIMER}

This document was prepared as an account of work sponsored by an agency of the United States Government. Neither the United States Government nor the University of California nor any of their employees, makes any warranty, express or implied, or assumes any legal liability or responsibility for the accuracy, completeness, or usefulness of any information, apparatus, product, or process

disclosed, or represents that its use would not infringe privately owned rights. Reference herein to any specific commercial product, process, or service by trade name, trademark, manufacturer, or otherwise, does not necessarily constitute or imply its endorsement, recommendation, or favoring by the United States Government or the University of California. The views and opinions of authors expressed herein do not necessarily state or reflect those of the United States Government or the University of California, and shall not be used for advertising or product endorsement purposes. 


\title{
HIGH-PERFORMANCE INSULATOR STRUCTURES FOR ACCELERATOR APPLICATIONS*
}

\author{
S. E. Sampayan, G. J. Caporaso, D. M. Sanders, R. D. Stoddard, D. O. Trimble, \\ Lawrence Livermore National Laboratory, Livermore, CA 94551, and J. Elizondo, M. L. Krogh, \\ and T. F.Wieskamp, Allied Signal Corporation, FM\&T, Kansas City, MO 64141
}

Absract

A new, high gradient insulator technology has been developed for accelerator systems. The concept involves the use of alternating layers of conductors and insulators with periods of order $1 \mathrm{~mm}$ or less. These structures perform many times better (about 1.5 to 4 times higher breakdown electric field) than conventional insulators in long pulse, short pulse, and alternating polarity applications. We describe our ongoing studies investigating the degradation of the breakdown electric field resulting from alternate fabrication techniques, the effect of gas presssure, the effect of the insulator-toelectrode interface gap spacing, and the performance of the insulator structure under bi-polar stress.

\section{INTRODUCTION}

It is experimentally observed that insulators composed of finely spaced alternating layers of dielectric $(<1 \mathrm{~mm})$ and thin metal sheets have substantially greater vacuum surface flashover capability than insulators made from a single uniform substrate [1]. In the previous work we showed these structures to sustain electric fields 1.5 to 4 times that of a similar conventional single substrate insulator [2]. We also previously reported on the capability of these structures under various pulse conditions and in the presence of a cathode and electron beam. Further, we have explored the properties of these structures in the context of switching applications, investigating their behavior under high-fluence photon bombardment [3] and the effect on RF modes [4,5]. Here we describe our on-going studies on the degradation of the breakdown electric field resulting from alternate fabrication techniques, the effect of gas pressure, the effect of the insulator-to-electrode interface gap spacing and on initial testing that subjects the insulator to bi-polar pulses.

A high-gradient insulator consists of a series of very thin $(<1 \mathrm{~mm})$ stacked laminations interleaved with conductive planes. This insulator technology was originally conceived and disclosed by Eoin Gray in the early 1980's [6] and resulted from experimental observations that the threshold electric field for surface flashover increases with deceased insulator length $[7,8]$.

Some understanding of the increased breakdown threshold of these structures may be realized from the basic model of surface flashover. A simplified vacuum surface breakdown model suggests that electrons originating from the cathode-insulator junction are responsible for initiating the failure [9]. When these electrons are intercepted by the insulator, additional electrons, based on the secondary emission coefficient of the surface, are liberated. This effect leaves a net positive charge on the insulator surface, attracting more electrons and leading to escalation of the effect or SEEA breakdown.
It has been shown that full evolution of the discharge occurs within $0.5 \mathrm{~mm}$ [10]. Thus, placing slightly protruding metallic structures at an equivalent interval is believed to interrupt the SEEA process and allow the insulator to achieve higher gradients before failure. Alternate modifications to this explanation include the effects of insulator shielding and equilibration of the induced surface charge. As a result, electron impact on the surface is modified. Or, alternately, by separation of the insulator into $\mathrm{N}-1$ additional decoupled sub-structures, a local breakdown on the insulator cannot propagate to the remainder of the structure.

In this paper we describe our on-going work in which we have performed additional studies on the effect of various fabrication techniques, the effect of gas pressure, the effect of the insulator-to-electrode interface spacing, and on initial testing which subjects the insulator to bipolar stress.

\section{APARATUS}

Small sample testing (approximately $2.5 \mathrm{~cm}$ diameter by $0.5 \mathrm{~cm}$ thick) was performed in a turbo-molecular pumped, stainless-steel chamber at approximately $10^{-6} \mathrm{~T}$. High voltage was developed with a $10 \mathrm{~J}$ "mini-Marx". The Marx developed a pulsed voltage of approximately 1 to $10 \mu$ s (base-to-base) and up to $250 \mathrm{kV}$ amplitude across the sample. Diagnostics consisted of an electric field sensor and a current viewing resistor. Failure of the insulator was determined by a prompt increase in Marx current and a prompt collapse in the voltage across the sample.

Several small sample insulators were fabricated by interleaving layers of $0.25 \mathrm{~mm}$ fused silica, formed by depositing gold on each planar insulator surface by a sputtering technique and then bonding. Bond strength between the gold layer and substrate using this technique was measured to exceed 10kpsi. Alternate samples were also fabricated from lexan and other polymer materials. To perform the breakdown experiments, the structure was slightly compressed between highly polished bare aluminum electrodes that establish the electric field for the tests.

After a short conditioning phase, we applied up to 150 to 200 shots to a given structure and attempted to determine if any damage to the structure occurred that significantly altered the breakdown characteristics. At these applied energies, we generally did not observe any degradation. These data were then reduced to reliability plots by determining the total number of successful shots over the total number of applied shots. In these data we define the electric field as the applied voltage divided by the total insulator length. We define reliability at a given electric field as the total number of successful shots over the total number of shots. 


\section{RESULTS}

We observed flashover of the small samples at approximately $175 \mathrm{kV} / \mathrm{cm}$ for the fused silica substrates (fig. 1). The effect of pulse width from 1 to $10 \mu$ s on this breakdown threshold was well within the statistical nature of our data. The trend in conventional insulator technology (fig. 2) for $0^{\circ}$-insulators indicates a threshold of approximately $50 \mathrm{kV} / \mathrm{cm}$. Thus, a net increase in the performance over conventional technology was a factor of approximately 3.5 .

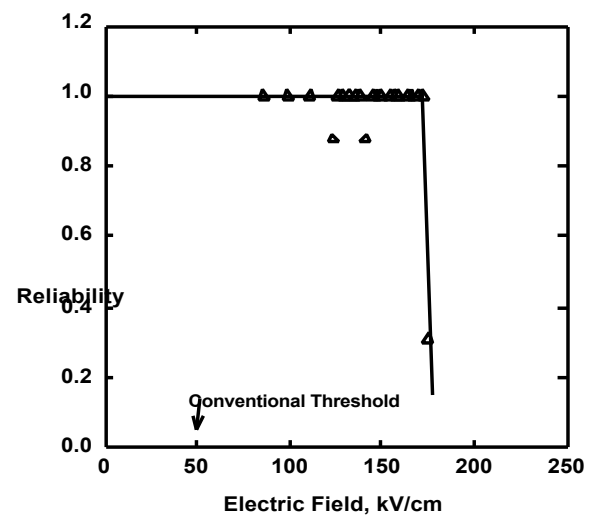

Figure 1. Pulsed surface breakdown reliability of a ground-fused silica high-gradient insulator.

A finish grinding operation was generally performed on the outside diameter. Since this process is timeconsuming, an alternate fabrication means was pursued. To simplify fabrication, we attempted an ultrasonic machining process. Although it was possible to fabricate the part in a single operation, the surface was left slightly rougher. Comparison with these samples showed significantly more scatter and a slightly decreased breakdown threshold of $25 \%$ (fig. 3 ).

The structures were also subjected to increased pressures to determine susceptibility to breakdown (fig. 4). In these data a fixed reliability was established at the various pressures. All data was then normalized to a mean breakdown electric field. Susceptibility to breakdown stays relatively constant up to about the $10^{-3} \mathrm{~T}$ range, at which point, the field at which breakdown occurs decreases rapidly. Also shown are data from previous work by Smith [11]. It appears that the new structures show a lower breakdown electric field threshold than that of the previous data at these elevated pressures.

Any insulator not in full contact with the electrode surface will show a higher susceptibility to breakdown and lower reliability at a given electric field. This effect results from the enhanced electric field that occurs between the insulator/electrode interface gap. To investigate this effect with these new structures, shims were placed between the cathode electrode and insulator, and the reliability at a given electric field were determined. This data, normalized to the configuration where the insulator was flush with the electrode, is shown figure 5. In these tests, we observed the reduction in the capability of the insulator to be strongly reduced from about $90 \%$ of full capability for a $12-\mu \mathrm{m}$ interface gap to less than $60 \%$ for a $125-\mu \mathrm{m}$ interface gap.

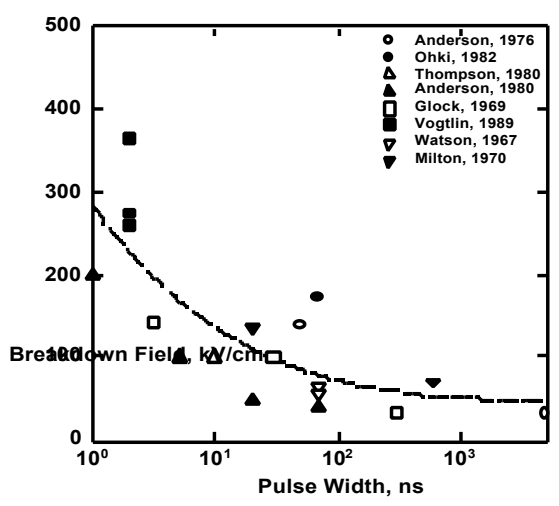

Figure 2. Pulsed surface breakdown electric field as a function of pulse width for single substrate, straight wall insulators.

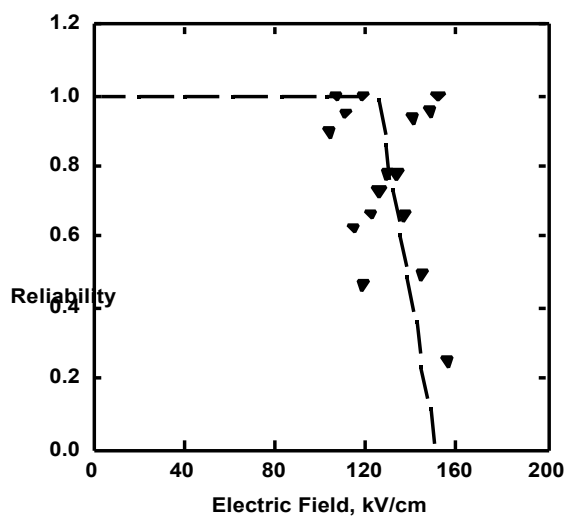

Figure 3. Pulsed surface breakdown reliability of a fused silica high-gradient insulator fabricated using an ultrasonic fabrication technique.

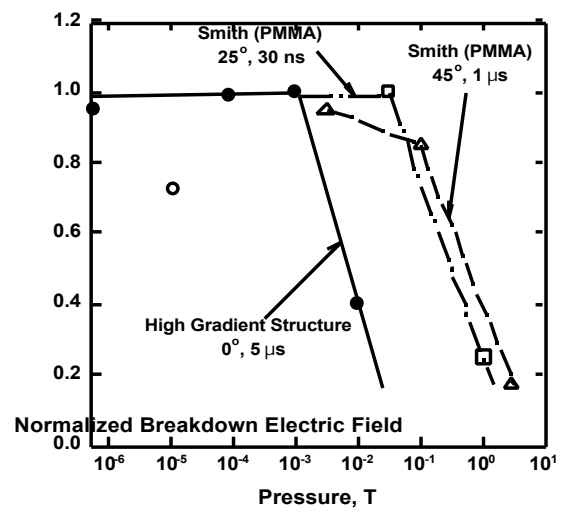

Figure 4. Effect of gas pressure on the performance of high-gradient insulators. 


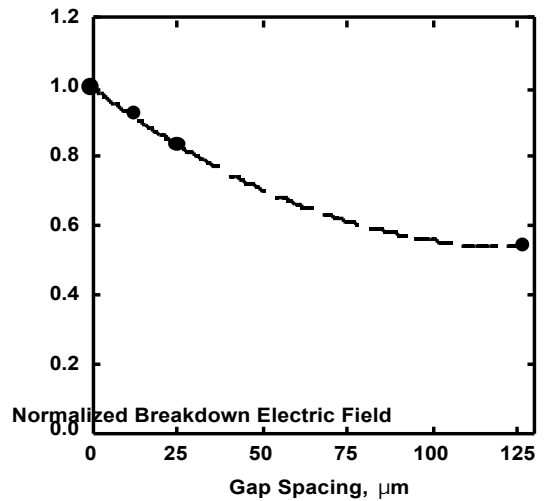

Figure 5. Effect of an increased electrode/insulator interface gap.

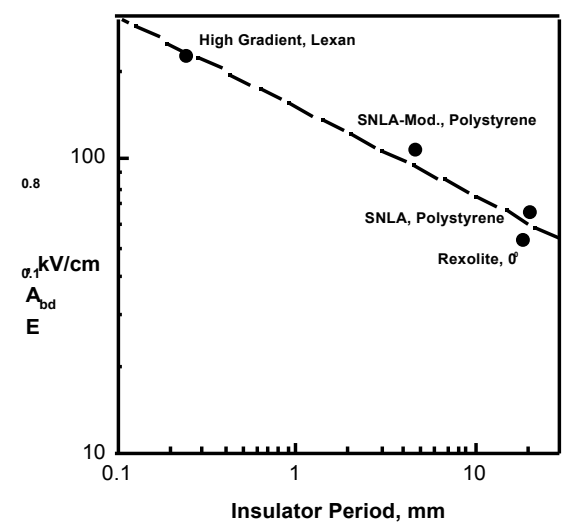

Figure 6. Result of bipolar testing of the high gradient insulator. Comparison with conventional data [12].

We have also begun testing these structures under bipolar stress. The applied pulses were generated by placing an inductor between the insulator and allowing the Marx generator to undergo un-damped oscillation $\left(\tau_{\mathrm{p}}=500 \mathrm{~ns}\right)$. This technique would subject the insulator structures to approximately 10 fully reversing pulses. Results are shown in figure 6 . Comparison with previous data, scaled to area, shows a strong dependence on the insulator period. Increased performance over conventional technology (Rexolite, $0^{\circ}$ ) was exceeded by a factor of 4 .

\section{SUMMARY}

We are developing a high gradient insulator technology for accelerator systems which consists of alternating layers of conductors and insulators with periods of order $1 \mathrm{~mm}$ or less. These structures perform many times better (about 1.5 to 4 times higher breakdown electric field) than conventional insulators in long pulse, short pulse, and alternating polarity applications.

\section{REFERENCES}

*Performed under the auspices of the US Dept. of Energy by LLNL under contract W-7405-ENG-48.

[1] J. Elizondo and A. Rodriguez, Proceedings of the 1992 15th International Symposium on Discharges and Electrical Insulation in Vacuum, Vde-Verlag Gmbh, Berlin, Germany, pp. 198-202.

[2] S. Sampayan, et. al., Proceedings of the 1995 Particle Accelerator Conference, (IEEE), New York, N.Y., pp.1269-1271.

[3] S. Sampayan, et. al., Proceedings of the 1995 Particle Accelerator Conference, (IEEE), New York, N.Y., pp. 2123-2125.

[4] T. L. Houck, et. al., these proceedings.

[5] C. C. Shang, et. al., these proceedings.

[6] E. Gray, private communication.

[7] O. Milton, IEEE Trans. Electr. Insul., Vol. EI-7, pp. 9-15.

[8] A. S. Pillai and R. Hackam, J. Appl. Phys., Vol. 53(4), pp. 2983-2987.

[9] H. C. Miller, G. E. Aerospace Report, (GEPP-TIS1064-UC-13).

[10]W. Glock and S. Linke, Cornell University Report, Laboratory of Plasma Studies, Ithaca, N.Y., (No. LPS 24, 1969).

[11]I. D. Smith, "Pulsed Breakdown of Insulator Surfaces in Poor Vacuum," unpublished AWRE report, Aldermaston, United Kingdom.

[12]R. A. Anderson and W. K. Tucker, J. Appl Phys., Vol. 58(8), pp. 3346-3349 


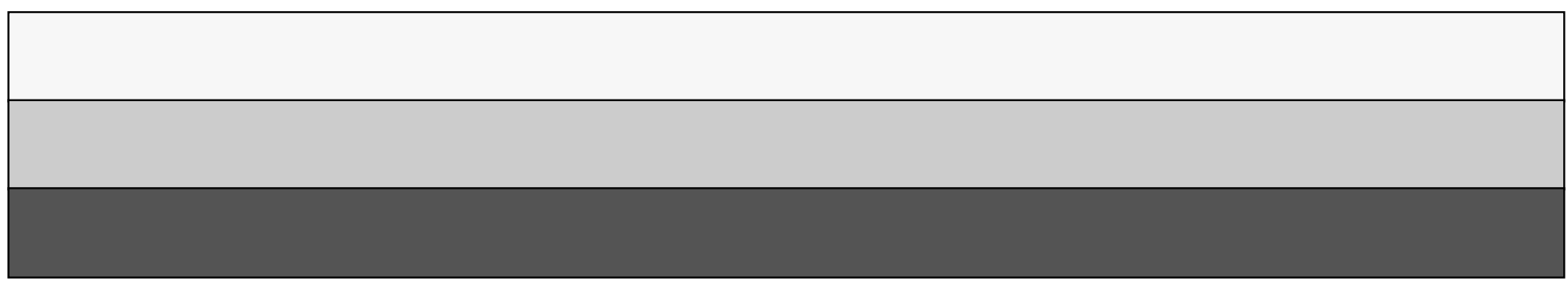

